\title{
Thermal Analysis of Thin-walled Deployable Composite Boom in Simulated Space Environment
}

\author{
J B Bai ${ }^{1}$, R A Shenoi², J J Xiong1, *
}

1 School of Transportation Science and Engineering, Beihang University, Beijing, 100191, People’s Republic of China (*, corresponding author: jjxiong@buaa.edu.cn)

2 Southampton Marine and Maritime Institute, University of Southampton, Southampton, UK

\begin{abstract}
This paper seeks to investigate thermal behaviour of a thin-walled deployable composite boom (DCB) in a space environment using ground thermal-vacuum test and FEA methods. Thermal tests simulating a space environment include three key conditions, namely ultra-high level of vacuum (lower than $\left.10^{-5} \mathrm{~Pa}\right)$, heat sink $\left(-180^{\circ} \mathrm{C}\right)$ that is realized using black panels with the liquid-nitrogen cooling system and thermal loading that is achieved through infrared lamps. The thermal tests of the DCB under seven typical heat fluxes were conducted to characterize heat transfer mechanisms and to obtain temperature fields. The basic heat transfer methods for the DCB in a space environment were surface radiation, cavity radiation and heat conduction. These led to significant temperature difference and gradient occurring on the irradiated and shadowed parts of the DCB at nighttime and daytime. FE models were established to predict temperature fields and thermally induced deformation. Good correlation was achieved between experimental and numerical results.
\end{abstract}

Key words: deployable; composite boom; thermal analysis; thermally induced deformation; space environment

\section{NOMENCLATURE}

$\begin{array}{ll}A & \text { area of body surface } \\ H & \text { orbit altitude } \\ I_{0} & \text { solar constant, } \mathrm{W} / \mathrm{m}^{2} \\ L & \text { distance between the Earth and the Sun, } \mathrm{km} \\ Q_{e} & \text { infrared radiation intensity of the Earth, } \mathrm{W} / \mathrm{m}^{2} \\ Q_{\mathrm{A}} & \text { surface radiation intensity of the Earth, W/m } / \mathrm{m}^{2} \\ R_{S} & \text { radius of the Sun, km }\end{array}$




$\begin{array}{ll}R_{e} & \text { radius of the Earth, km } \\ T_{1} & \text { thermodynamic temperature of a body surface, } \mathrm{K} \\ T_{2} & \text { thermodynamic temperature of a heat sink, } \mathrm{K} \\ \sigma & \text { Steffane-Boltzman constant } \\ \theta & \text { the maximum deflection of sunlight reaching the Earth, rad } \\ \Delta & \text { the maximum relative change of solar radiation intensity around the Earth } \\ \varepsilon & \text { infrared emissivity } \\ \tau & \text { transparence coefficient of atmosphere } \\ \rho_{\mathrm{g}} & \text { reflectivity } \\ \lambda & \text { transformation variable }\end{array}$

\section{INTRODUCTION}

Thin-walled deployable composite boom (DCB) structures of hinge and lenticular boom varieties are of considerable interest in the aerospace field, with typical examples shown in Figure $1^{[1-6]}$. Many investigations of these structures have been conducted to deal with the foldable properties and stiffness in a fully deployed state ${ }^{[7-12]}$. However, only a few investigations were focused on thermal behaviour of deployable composite structures in a space environment. The basic heat transfer mechanisms for a space vehicle include radiation and conduction, without convection owing to the vacuum condition. Significant temperature difference and gradient occur on the irradiated and shadowed parts of space vehicles under solar direct radiation and infrared radiation from the Earth at nighttime and daytime. This can further lead to thermal deformation or other problems affecting service properties. Therefore, characterizing and understanding thermal behaviour of thin-walled deployable composite structures is important.

It is expensive and difficult to carry out a true space thermal test or even a ground simulated one. Thus only a few experimental investigations have been openly reported. Frisch ${ }^{[13]}$ presented analytical solutions for determining bent and twisted deformations of a Gravity Gradient boom induced by a solar thermal field. It was shown that the thermal equilibrium shape of Gravity Gradient boom was not unique due to a planar assumption. Thus this method is more suitable for thermal deflection analysis of very long thin-walled members with open section. Thornton et al. ${ }^{[14]}$ 
proposed an analytical model to examine the reasons for thermal failure of the solar array on the Hubble space telescope. An approximate analytical solution for temperature distribution of the closed thin-walled circular tube was obtained by Fourier expansion of temperature in the circumferential direction and neglect of the conduction along the length of the tube. Thus temperature field in the cross section can be determined. This analytical method is not suitable for complex structures. Gulick and Thornton ${ }^{[15]}$ developed an analytical beam model to investigate thermally-induced motion of an axial boom of a spin-stabilized spacecraft. The stability of the coupled response was analyzed using the Floquet theory. It was found that unstable thermally-induced response was possible for parameters characteristic of a typical axial boom. Ishimura and Higuchi ${ }^{[16]}$ presented an analytical model to characterize the coupling effect between structural deformation and attitude motion of large planar space structures suspended by multi-tethers. It was shown that roll and yaw motions were unstable due to thermally induced deformation. Liu and $\operatorname{Pan}^{[17]}$ proposed a rigid-flexible-thermal coupling dynamic model for satellite and plate multibody systems. This model considers the influence of both the rotational motion and the elastic deformation on the heat flux applied on the elastic bodies. The coupling effect of both the rotational motion and elastic deformation on the temperature gradient and the thermally induced fluttering effect can be evaluated using their model. Givoli et al. ${ }^{[18]}$ developed a numerical model to analyze large truss-type space structures undergoing periodic motion through Fourier decomposition in time and finite elements in space. Both the temperature field and the displacement field in structures were obtained. In numerical examples, the transition between the quasi-steady state and dynamic state in thermal elastic analysis was discussed. Yang et al. ${ }^{[19,20]}$ simulated the temperature field of a solar array of the spacecraft. The period change rule of the temperature field and the characteristic of temperature distribution of the solar array were revealed. Block and Leipold et al. ${ }^{[5,21]}$ analyzed the temperature distribution of collapsible composite lenticular tubes under solar radiation and investigated the influence of coatings on temperature field using FEA method. Howerver, the simulated results indicated that the cavity radiation effect on temperature field was not considered in the FE model. This led to non-existence of a temperature gradient in axial direction. Taylor et al. ${ }^{[22]}$ experimentally investigated the foldable ability of elastic memory composite booms in a ground thermal vacuum environment. Passive deployment of the booms was successfully demonstrated. They preliminarily explored the possibility of simulated space environment test for deployable composite structures. 
From the above reviews, it is clear that thermal behaviour of conventional space structures have been investigated reasonably well using theoretical methods, but still lacking of experimental investigations. Thus, there is the scope for improving our understanding thermal behaviour of the thin-walled DCB. The DCB is receiving more attention and application in aerospace engineering due to superior mechanical properties and packaging convenience. It is important to characterize the thermal behaviour of the DCB in space environment. This paper, therefore, makes an effort to provide an insight into thermal tests simulating a space environment to obtain thermal behaviour of the DCB. FE models are established to predict temperature distribution and thermally induced deformation.

\section{THERMAL EXPERIMENT OF SIMULATED SPACE ENVIRONMENT}

\subsection{Scheme Design}

The basic heat transfer mechanisms of structures in a space environment include radiation and conduction owing to the vacuum condition. The heat sink of the space, solar radiation and infrared radiation from the Earth are considered as the main external heat sources. The heat sink temperature of the space is $4 \mathrm{~K}$. The solar constant is ${ }^{[23]}$

$$
I_{0}=1367 \mathrm{~W} / \mathrm{m}^{2}
$$

Figure 2 shows relative location of the Sun and the Earth. The distance between the Earth and the Sun $L$ is $1.5 \times 10^{8} \mathrm{~km}$. The radius of the Sun $R_{s}$ is $6.957 \times 10^{5} \mathrm{~km}$. The radius of the Earth $R_{e}$ is 6371 km. From geometrical relationships shown in Figure 2, it is possible to obtain the maximum change of solar radiation intensity around the Earth as

$$
\Delta=\frac{I_{0}-I_{0} \cos \theta}{I_{0}} \times 100 \%=\left(1-\frac{\sqrt{\left(R_{s}+R_{e}+L\right)^{2}-R_{e}^{2}}}{R_{s}+R_{e}+L}\right) \times 100 \%=8.94 \times 10^{-8} \%
$$

This is so small that the change can be completely neglected, and the sunlight can be then idealized as the parallel light with a constant solar radiation intensity.

The solar radiation energy absorbed by the Earth is emitted from the Earth by the form of infrared radiation. The infrared radiation intensity of the Earth can be described as ${ }^{[23]}$

$$
Q_{e}=\tau I_{0} R_{e}^{2} \frac{1-\rho_{\mathrm{g}}}{4\left(R_{e}+H\right)^{2}}
$$


where $\tau$ is the transparence coefficient of atmosphere with the value of $0.9^{[23]}, H$ is orbit altitude and $\rho_{\mathrm{g}}$ is the reflectivity with the value of $0.3^{[23]}$. From Equation (3), heat flux of infrared radiation of the Earth versus orbit altitude can be obtained (shown in Figure 3). From Figure 3, it is clear that heat flux of infrared radiation of the Earth decreases with the orbit altitude. The maximum heat flux is about $200 \mathrm{~W} / \mathrm{m}^{2}$.

Figure 4 shows a solar sail spacecraft based on the DCB. The length of the DCB is commonly several dozens or hundreds of meters. Thus, significant thermally induced deformation occurs due to temperature difference and gradient on the irradiated and shadowed parts of the DCB. Figure 5 shows heat transfer mechanisms of thin-walled cavity structures in space environment. Heat sink, solar radiation, infrared radiation of the Earth, heat conduction, surface radiation and cavity radiation have influences on temperature field of the DCB. This poses a serious challenge to techniques used for a thermal testing in laboratories of the simulated space environment.

Three key indispensable conditions for the thermal test of the simulated space environment in this paper include:

- Ultra-high vacuum level that is lower than $10^{-5} \mathrm{~Pa}$

- Ultra-black and cold heat sink of $93.15 \mathrm{~K}$ (i.e.- $180^{\circ} \mathrm{C}$ ) that is realized by using black panels with the liquid-nitrogen cooling system

- Thermal loading (i.e. heat flux) that is obtained through infrared lamp array

In the thermal test, the heat sink temperature of $93.15 \mathrm{~K}$ (i.e. $-180{ }^{\circ} \mathrm{C}$ ) is chosen rather than $4 \mathrm{~K}$ (i.e. $-269{ }^{\circ} \mathrm{C}$ ), because it is too costly to simulate the latter.

According to radiation rule

$$
Q_{\mathrm{A}}=\varepsilon A \sigma\left(T_{1}^{4}-T_{2}^{4}\right)
$$

where $T_{1}$ is the thermodynamic temperature of a body surface, $T_{2}$ is the thermodynamic temperature of a heat sink, $\varepsilon$ is the infrared emissivity, $A$ is the area of body surface and $\sigma$ is the Steffane-Boltzman constant (i.e. $\left.5.67 \times 10^{-8} \mathrm{~W} /\left(\mathrm{m}^{2} \mathrm{~K}^{4}\right)\right)$.

Transforming Equation (4), one has

$$
Q_{\mathrm{A}}=\varepsilon A \sigma(1-\lambda) T_{1}^{4}
$$

with 


$$
\lambda=\frac{T_{2}^{4}}{T_{1}^{4}}
$$

where $\lambda$ is the transformation variable which can be used to depict the effect of the body surface temperature on infrared radiation.

Assuming the temperature range of a body surface is $T_{1} \in[-173.15 K, 373.15 K]$ or $T_{1} \in\left[-100^{\circ} \mathrm{C}, 100^{\circ} \mathrm{C}\right]$ and substituting the temperatures into Equation (6) leads to

$$
\left\{\begin{array}{l}
0.0038 \leq \lambda \leq 0.0838 \quad\left(T_{2}=93.15 \mathrm{~K}\right) \\
1.32 \times 10^{-8} \leq \lambda \leq 2.85 \times 10^{-7} \quad\left(T_{2}=4 \mathrm{~K}\right)
\end{array}\right.
$$

Equation (7) shows the influence of the laboratory testing heat sink temperature and the true space heat sink temperature on infrared radiation. The maximum influence of heat sink temperature on infrared radiation is less than $8.38 \%$. Hence the laboratory testing heat sink temperature can be used to reasonably simulate the true space environment; This satisfies the thermal analysis requirements from an engineering perspective.

\subsection{Thermal Test}

The geometry and dimensions of the DCB specimen used for thermal test are shown in Figure 6. The specimen was made up of both the same axisymmetrical curved thin-walled carbon-fiber-reinforced-plastics shells with three tangent arcs (i.e. a convex arc with 60 mm radius and $120^{\circ}$ central angle and [45/0/-45/0/-45/0/45] plies, and two concave arcs with $60 \mathrm{~mm}$ radius and $60^{\circ}$ central angle and [45/-45/0/-45/45] plies) and two horizontal bonding flanges with $16 \mathrm{~mm}$ width by co-bonding technique. The ply thickness is $0.03 \mathrm{~mm}$. The specimen length is $1000 \mathrm{~mm}$.

Space structures only undertake infrared radiation of the Earth at night and mainly subjects solar radiation in a relative high orbit altitude at daytime. Thus, the heat flux loadings were monolithically loaded on the DCB specimen. According to the analysis of the section 2.1, the values of heat flux is selected from $200 \mathrm{~W} / \mathrm{m}^{2}$ to $1400 \mathrm{~W} / \mathrm{m}^{2}$, in seven steps.

Figure 6 details the temperature sensor arrangement locations for thermal test. Thirty temperature sensors were arranged in parallel on the top and bottom shells of the DCB following five rows in Y direction and three columns in $\mathrm{X}$ direction. Five temperature sensors in each column were respectively arranged at the apex of convex arc, the tangent points between convex arc and concave arcs, and the middle points of horizontal straight flanges. Three temperature sensors in each row 
were arranged along longitudinal direction with a spacing interval of $250 \mathrm{~mm}$. The DCB specimen with arranged temperature sensors is shown in Figure 7(a). The thermal test system was established according to the scheme design mentioned in section 2.1 (shown in Figure 7b), including vacuum tank, heat sink, infrared lamps, DCB specimen, heat flow meters, temperature sensors, etc. The heat flux can be accurately controlled by changing the power of infrared lamps. The heat flux loaded on the specimen was measured by heat flow meters and was captured as a feedback to the heat flux control system. The thermal test was started after confirming all test conditions (shown in Figure 7d). Firstly vacuuming was carried out. The precool system worked when the vacuum degree was lower than $10^{-5} \mathrm{~Pa}$. The infrared lamps were lit once the heat sink temperature was below $93.15 \mathrm{~K}$ (i.e. $-180^{\circ} \mathrm{C}$ ). The specimen under the lit infrared lamps is shown in Figure 7(c). The heat flux load on the DCB increased from $200 \mathrm{~W} / \mathrm{m}^{2}$ to $1400 \mathrm{~W} / \mathrm{m}^{2}$ in seven steps of $200 \mathrm{~W} / \mathrm{m}^{2}$ increasements. There are seven heat flux conditions. The steady thermal equilibrium state of the DCB under a heat flux should be kept for more than half an hour before recording the temperature data.

Temperature fields of thermal tests on DCB are shown in Figures 8 and 9. Only two representative temperature fields corresponding to heat flux $200 \mathrm{~W} / \mathrm{m}^{2}$ to $1400 \mathrm{~W} / \mathrm{m}^{2}$ (shown in Figures 8 and 9) are given due to the similar profile of the pictures. From Figures 8 and 9, it is clear that the temperature levels on irradiated part are higher than the ones on shadowed part. The highest temperature is located in the central range of the convex arc near the middle-section of the irradiated part (shown in Figures 8a and 9a). The lowest temperature is located in the central range of the convex arc near the end section of the shadowed part (shown in Figures 8b and 9b). The temperature gradient occurs along longitudinal direction. The temperature level of the whole DCB increases with heat flux. The experimental highest and lowest temperatures versus heat flux are shown in Figure 10 and Table 1. From Figure 10 and Table 1, the highest and lowest temperatures of the DCB under the heat flux $200 \mathrm{~W} / \mathrm{m}^{2}$ corresponding to thermal load at night are $217 \mathrm{~K}$ and 168.2 K; the highest and lowest temperatures of the DCB under the heat flux $1400 \mathrm{~W} / \mathrm{m}^{2}$ corresponding to thermal load at daytime are $339.5 \mathrm{~K}$ and $221.6 \mathrm{~K}$. A significant temperature difference and gradient occur on the irradiated and shadowed parts of the DCB at night and daytime. 


\section{THERMAL ANALYSIS}

\subsection{Temperature Distribution}

A 3D FE model of the DCB used for heat transfer analysis is established by ABAQUS code (shown in Figure 11a). A layered shell element DS8 that is an 8-node heat transfer quadrilateral shell element is employed, and the total number of elements is 1040. The outside surfaces and flanges of the DCB are modelled with a surface radiation characteristic. The inside surfaces of the DCB are modelled with a cavity radiation characteristic. The heat flux is loaded on the irradiated part of the DCB by analytical field method in ABAQUS code. The normal component of heat flux is shown in Figure 11(b). The relevant thermal material properties used in heat transfer FE model are listed in Table 2.

Temperature fields of the DCB under seven heat fluxes corresponding to the thermal test are calculated. Figures 12 and 13 show the temperature distribution of the DCB under two extreme heat fluxes. From Figures 12 and 13, it is obvious that the temperature levels on irradiated part are higher than the ones on shadowed part. This can be attributed to that the irradiated part directly receives the heat flux as a heat source while the shadowed part obtains heat by inefficient heat transfer methods such as the infrared cavity radiation and heat conduction of flanges. The highest temperature is located in the central range of the convex arc near the middle-section of the irradiated part (shown in Figures 12 and 13). The lowest temperature is located in the central range of the convex arc near the end-section of the shadowed part (shown in Figures 12 and 13). The temperature gradient occurs along longitudinal direction due to cavity radiation effect. The temperature level of the whole DCB increases with heat flux. The predicted highest and lowest temperatures versus heat flux are shown in Figure 10 and Table 1. The maximum relative deviations of the highest and lowest temperatures between numerical simulations and experiments are $4.23 \%$ and 7.96 \% respectively. The numerical simulations agree well with experiments. From Figure 10, it can be observed that the simulated curve of heat sink $93.15 \mathrm{~K}$ almost equals to the one of heat sink $4 \mathrm{~K}$. This also proves reasonability for adopting the heat sink temperature $93.15 \mathrm{~K}$ rather $4 \mathrm{~K}$ in thermal test in another perspective. Figure 14 shows the calculated temperature versus normalized distance along length direction on the top and bottom paths of the DCB. The temperature gradually increases from end-section to middle-section and tends to be a constant from 1/5 length with zero temperature gradient. Temperature gradient on the shadowed part are distinctly higher than the one 
on the irradiated part, especially for the case of the relative lower heat flux. This is caused by the effect of the surface radiation and cavity radiation on heat transfer, namely the range near the end-section loses more heat than other parts. These simulated results correlate well with experiments.

\subsection{Thermally Induced Deformation}

A 3D FE model of the DCB used for thermally induced deformation analysis is established by ABAQUS code. The mesh is the same as the one of the heat transfer FE model (shown in Figure 11a). A layered shell element S8R that is an 8-node heat doubly curved shell element is employed, and the total number of elements is 1040 . The symmetrical boundary condition on the middle section of the DCB is adopted (shown in Figure 15). Room temperature of $298.15 \mathrm{~K}$ is chosen as the initial temperature used in thermal deformation analysis. As the thermal loadings, the temperature fields obtained using heat transfer FE model are imported into the FE model used for thermal deformation analysis. The relevant mechanical material properties used in this FE model are listed in Table 2.

Figures 16 and 17 show the thermal deformation of the DCB under three heat fluxes. The displacement in $\mathrm{Y}$ direction is used to describe thermally induced bending of the DCB. From Figures 16 and 17, it is obvious that the thermally induced bending increases with heat flux. The maximum thermal deformations occur at the end-section of the DCB. Thus the significant temperature difference and gradient on the irradiated and shadowed parts can lead to distinct bending deformation.

In summary, an experimental and numerical thermal analysis method for the thin-walled DCB under space environment is proposed in this paper. The experimental data and numerical simulations of seven heat flux conditions were obtained. Experimental results correlate well with numerical simulations. Both the experiments and simulations indicate that a significant temperature difference and gradient occur on the irradiated and shadowed parts of the DCB at night and daytime. This can lead to distinct bending deformation. In addition, the thermal analysis method presented in this paper is also capable of being used to evaluate thermal behaviour of other space composite structures. The authors had intended to measure the thermal distortion of the boom in this extreme environment to validate the FE model. However, some presently insolvable technical challenges persist. The 3D Digital Image Correlation is commonly used to measure structural deformation. 
However, visibility in the tank is very limited due to simulating the heat sink of the space environment. It is too dark to capture clear image of the boom. Moreover, the ultra low temperature is very harsh for the measuring system. So the experimental measurements of the thermal distortion of the boom could not be obtained. Notwithstanding this limitation, the experiments nevertheless have shed new light on our understanding of DCB in space.

\section{CONCLUSIONS}

The thermal behaviour of the DCB in space environment were investigated using ground simulated testing and FEA methods. The heat transfer mechanism and thermally induced deformation were analyzed. Significant results emerging from the studies are as follows.

(1) An experimental and numerical thermal analysis methods for the thin-walled DCB under space environment were proposed in this paper. The experimental data and numerical simulations of seven heat flux conditions were obtained. A significant temperature difference and gradient occur on the irradiated and shadowed parts of the DCB at night and daytime due to inefficient heat transfer methods such as the infrared cavity radiation and conduction of flanges.

(2) The surface radiation, cavity radiation and the structural heat conduction were considered in the FE models that can accurately simulate the temperature fields in all heat flux conditions. Thermally induced deformation of the DCB was numerically simulated. The numerical simulations indicate that the significant temperature difference and gradient on the irradiated and shadowed parts can lead to distinct bending deformation.

\section{ACKNOWLEDGEMENTS}

This project was supported by the National Natural Science Foundation of China (Grant No. 51405006 and 51375033).

\section{REFERENCES}

[1] Leipold M, Fichtner H, Heber B, Groepper P, Lascar S, Burger F, Eiden M, Niederstadt T, Sickinger C, Herbeck L, Dachwald B, Seboldt W. Heliopause Explorer-a sailcraft mission to the outer boundaries of the solar system. Acta Astronautica, 2006; 59: 785-796. 
[2] Soykasap Ö. Folding design of composite structures. Composite Structures, 2007; 79: 280-287.

[3] Norman AD, Seffen KA, Guest SD. Morphing of curved corrugated shells. International Journal of Solids and Structures, 2009; 46: 1624-1633.

[4] Soykasap Ö. Deployment analysis of a self-deployable composite boom. Composite Structures, 2009; 89: 374-381.

[5] Block J, Straubel M, Wiedemann M. Ultra-light deployable booms for solar sails and other large gossamer structures in space. Acta Astronautica, 2011; 68: 984 - 992.

[6] Mallikarachchi HMYC, Pellegrino S. Quasi-static folding and deployment of ultrathin composite tape-spring hinges. Journal of Spacecraft and Rockets, 2011; 48(1): 188-197.

[7] Bai JB, Xiong JJ, Gao JP, Yi XS, Zhang ZL, He XC, Liu ZZ, Li XQ. Fabrication and validation of collapsible composite lenticular tubes. Acta Aeronautica et Astronautica Sinica, 2011; 32(7):1217-1223;

[8] Bai JB, Xiong JJ, Gao JP, Yi XS. Analytical solutions for predicting in-plane strain and interlaminar shear stress of ultra-thin-walled lenticular collapsible composite tube in fold deformation. Composite Structures, 2013; 97: 64-75.

[9] Stabile A, Laurenzi S. Coiling dynamic analysis of thin-walled composite deployable boom. Composite Structures, 2014; 113: 429-436.

[10]JB Bai, JJ Xiong. Temperature effect on buckling properties of ultra-thin-walled lenticular collapsible composite tube subjected to axial compression. Chinese Journal of Aeronautics, 2014; 27(5): 1312-1317.

[11]Barbera D, Laurenzi S. Nonlinear buckling and folding analysis of a storable tubular ultrathin boom for nanosatellites. Composite Structures, 2015 ;132: 226-238.

[12]Roh JH, Kim HI, Lee SY. Viscoelastic effect on unfolding behaviors of shape memory composite booms. Composite Structures, 2015; 133: 235-245.

[13]Frisch HP. Thermal bending plus twist of a thin-walled cylinder of open section with application to gravity gradient booms. NASA technical note. NASA TN D 4069.

[14]Thornton EA, Kim YA. Thermally induced bending vibrations of flexible rolled-up solar array. Journal of Spacecraft and Rocket, 1993; 30(4): 438-448.

[15]Gulick DW, Thornton EA. Thermally-induced vibrations of a spinning spacecraft boom. Acta Astronautica, 1995; 36(3): 163-176.

[16]Ishimura K, Higuchi K. Coupling between structural deformation and attitude motion of large 
planar space structures suspended by multi-tethers. Acta Astronautica, 2007; 60: 691-710.

[17]Liu J, Pan K. Rigid-flexible-thermal coupling dynamic formulation for satellite and plate multibody system. Aerospace Science and Technology, 2016; 52:102-114.

[18]Givoli D, Rand O. Thermo-elastic Analysis of Space Structure in Periodic Motion. Journal of Spacecraft and Rockets, 1991; 4: 457-464.

[19]Yang WH, Cheng HE, Cai A. Thermal analysis for folded solar array of spacecraft in orbit. Applied Thermal Engineering, 2004; 24(4): 595-607.

[20]Li P, Cheng HE, Qin WB. Numerical simulation of temperature field in solar array of spacecraft in low Earth orbit. Numerical Heat Transfer, 2006; 49( 8): 803-820.

[21]Leipold M, Fichtner H, Heber B, Groepper P, Lascar S, Burger F, Eiden M, Niederstadt T, Sickinger C, Herbeck L, Dachwald B, Seboldt W. Heliopause Explorer-a sailcraft mission to the outer boundaries of the solar system. Acta Astronautica, 2006; 59: 785-796.

[22] Taylor RM, Abrahamson E, Barrett R, Codell DE, Keller PN. Passive deployment of an EMC boom using radiant energy in thermal vacuum. $48^{\text {th }}$ AIAA/ASME/ASCE/AHS/ASC Structures, Structural Dynamics, and Materials Conference. 23-26 April 2007, Honolulu, Hawaii, AIAA Paper No. 2007-2269.

[23]Xiong JJ, Bai JB, Chen L. Simplified analytical model for predicting the temperature of balloon on high-altitude. International Journal of Thermal Sciences, 2014; 76: 82-89.

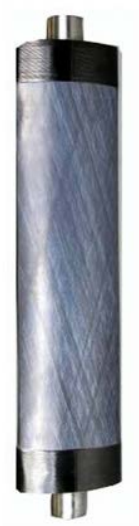

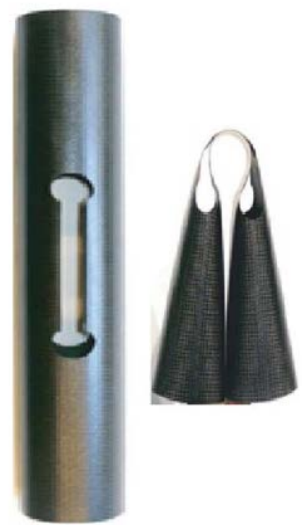

(a) Hinges

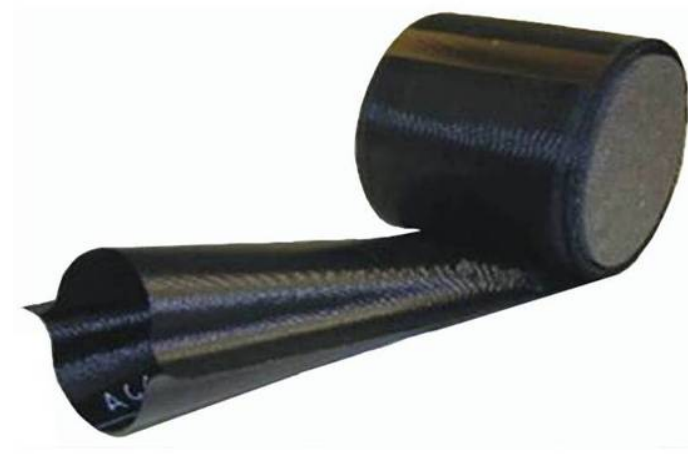

(b) Lenticular boom

Figure 1 Thin-walled deployable composite structures 


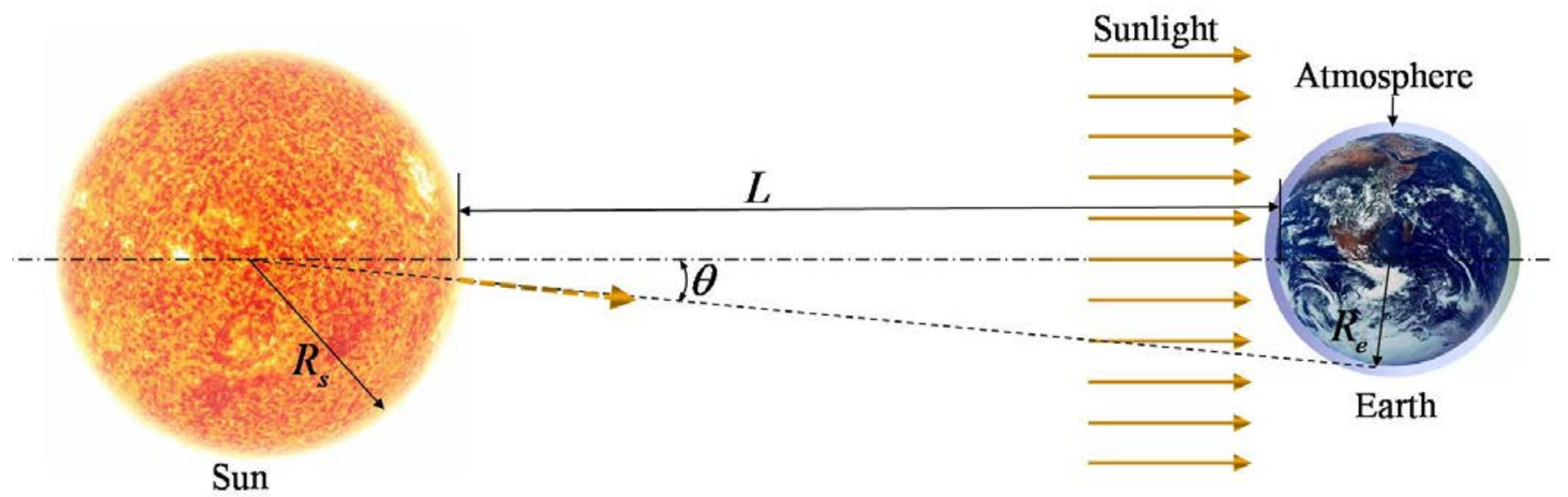

Figure 2 Relative location of the Sun and the Earth

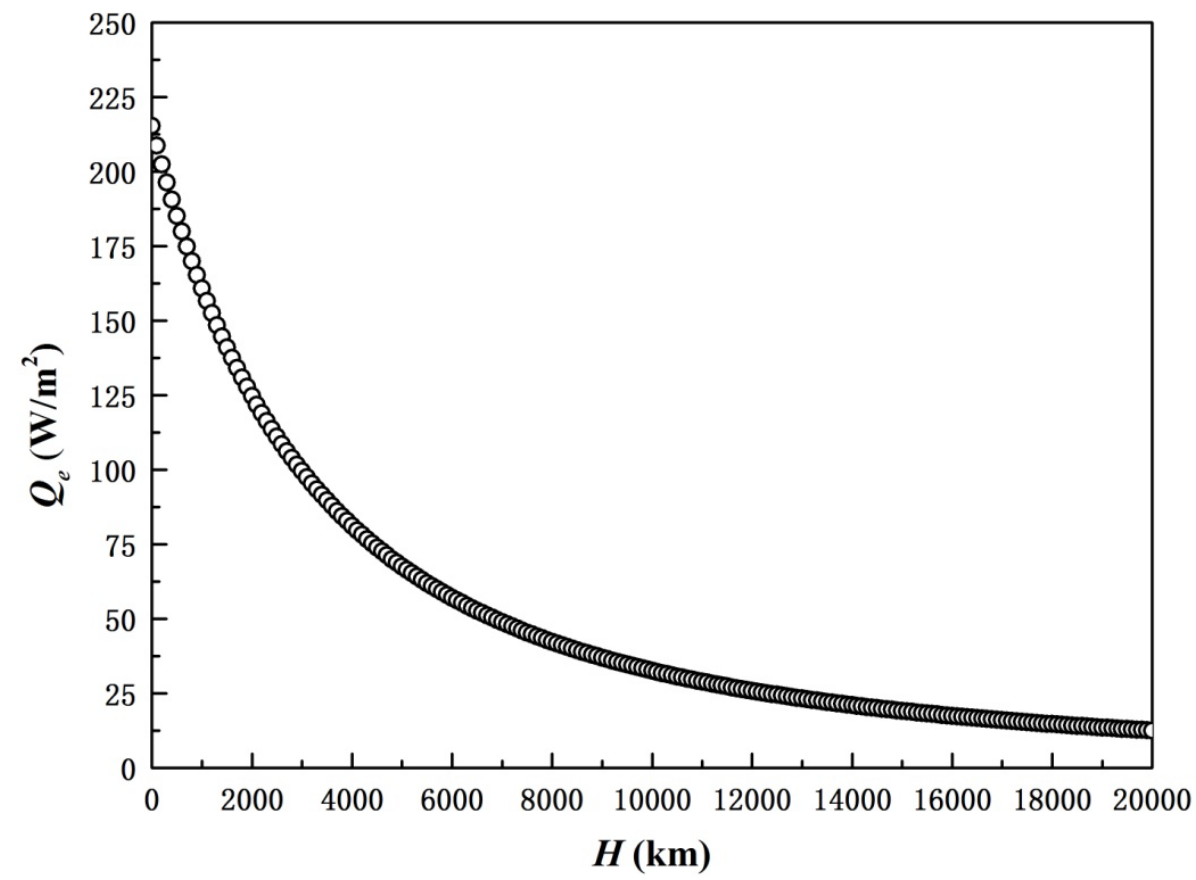

Figure 3 Heat flux of infrared radiation of the Earth versus orbit altitude 

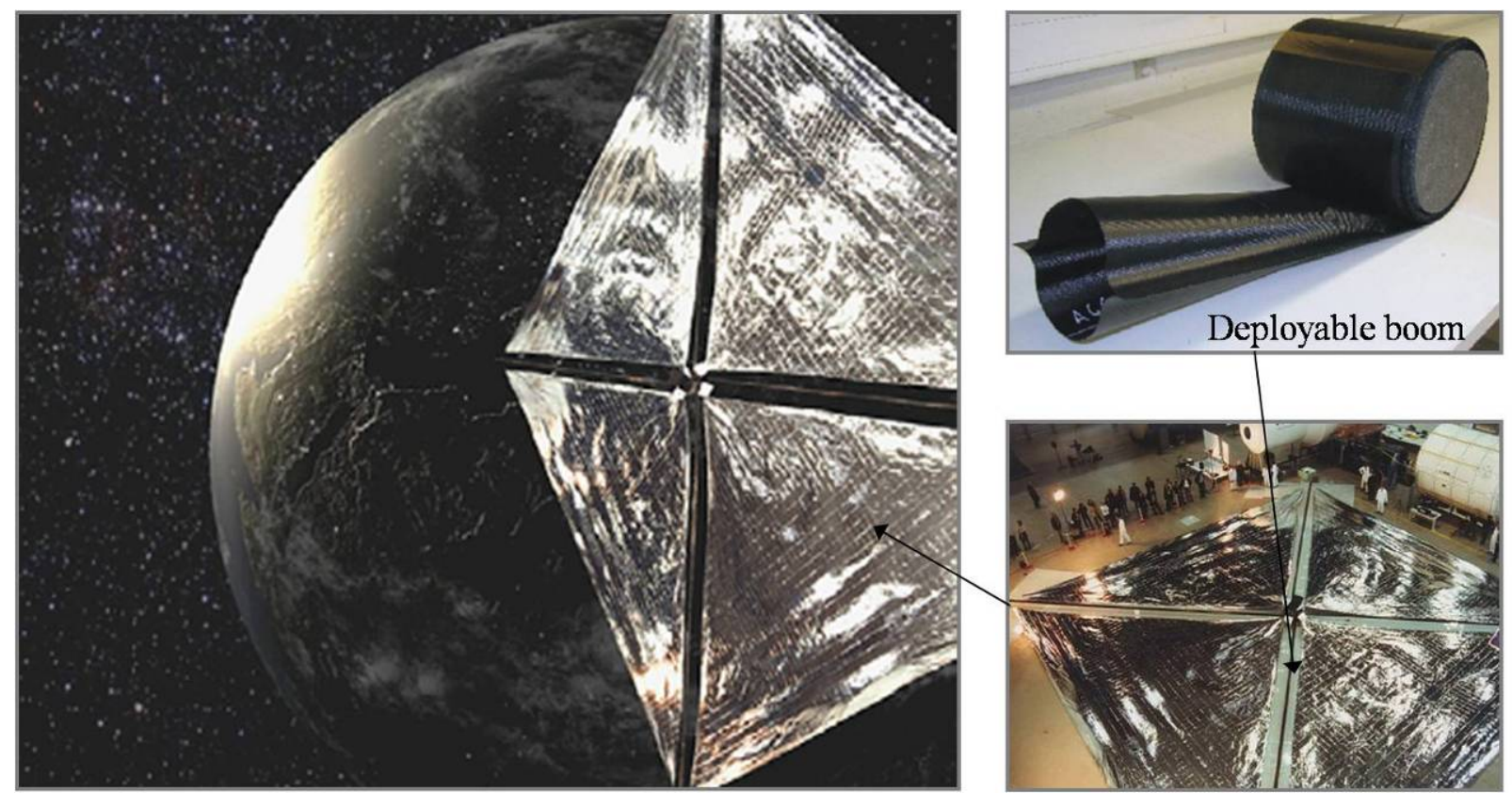

Figure 4 Solar sail spacecraft based on the DCB

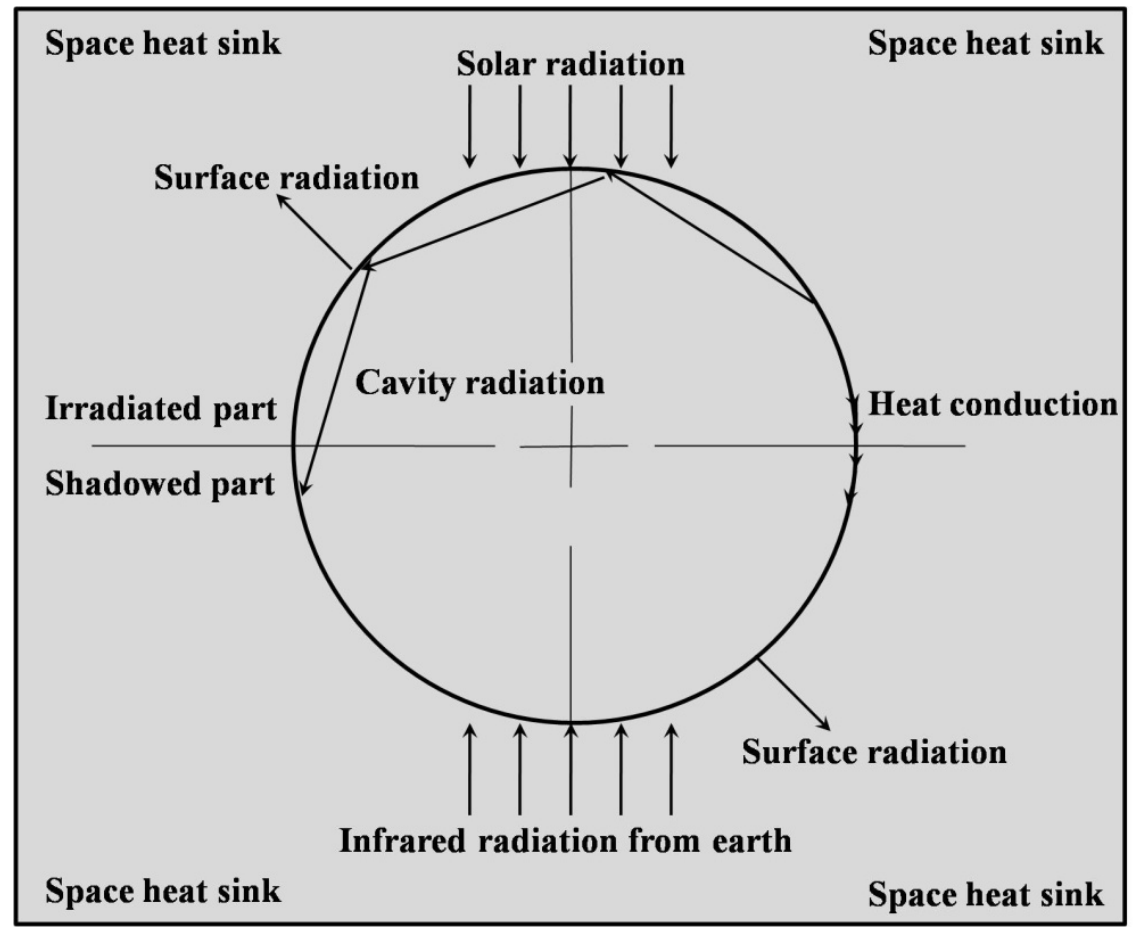

Figure 5 Heat transfer mechanisms of thin-walled cavity structures in space environment 

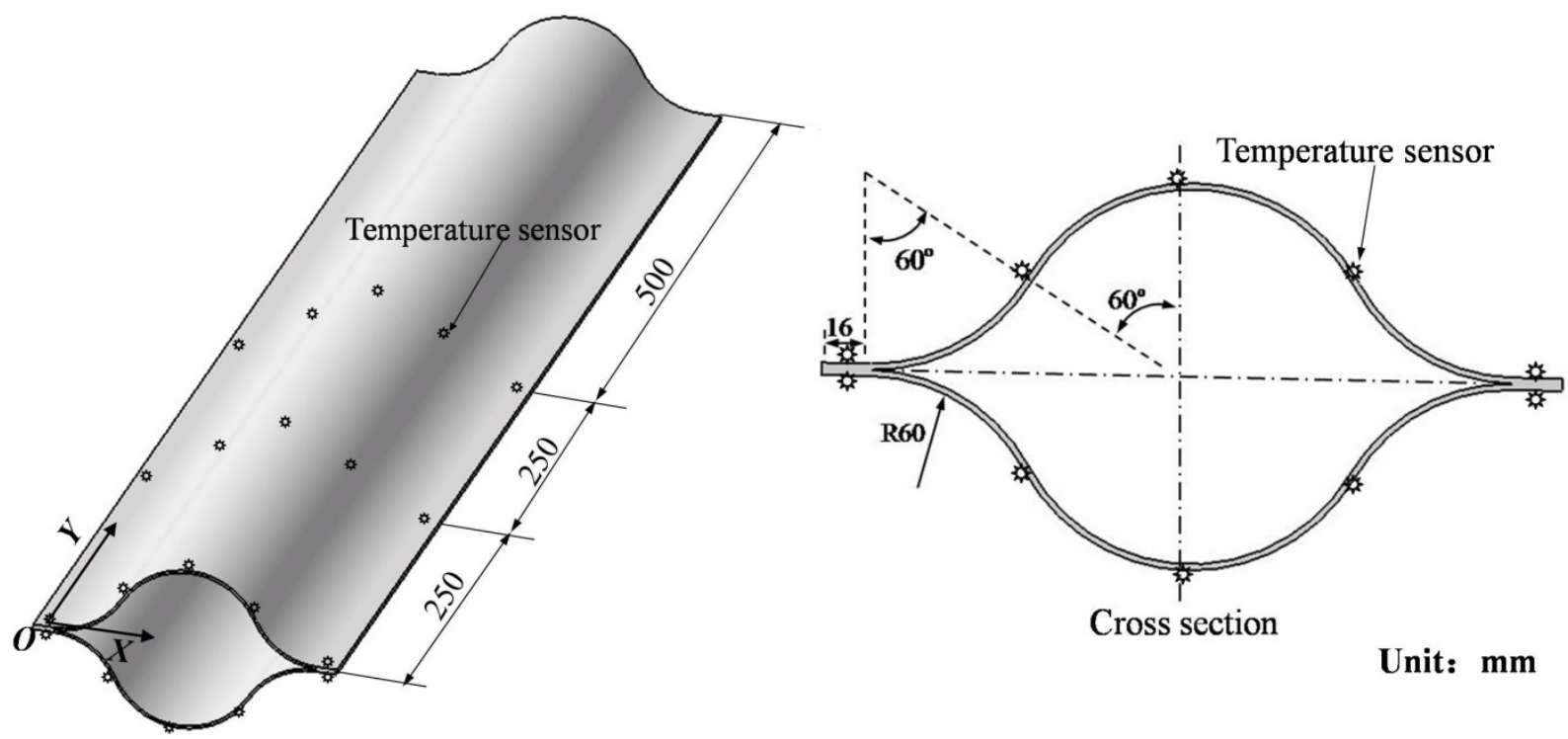

Figure 6 Temperature sensor arrangement for the thermal test

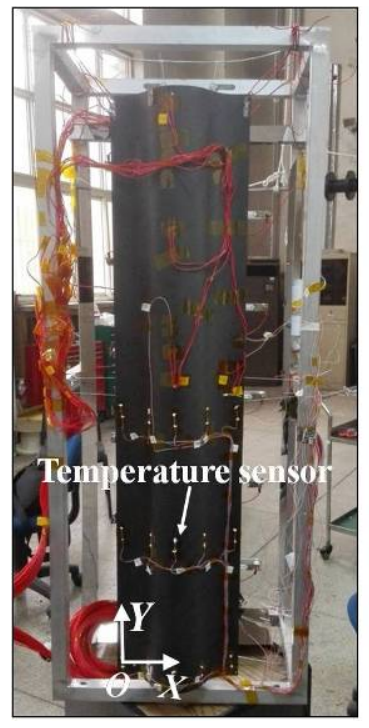

(a) DCB Specimen

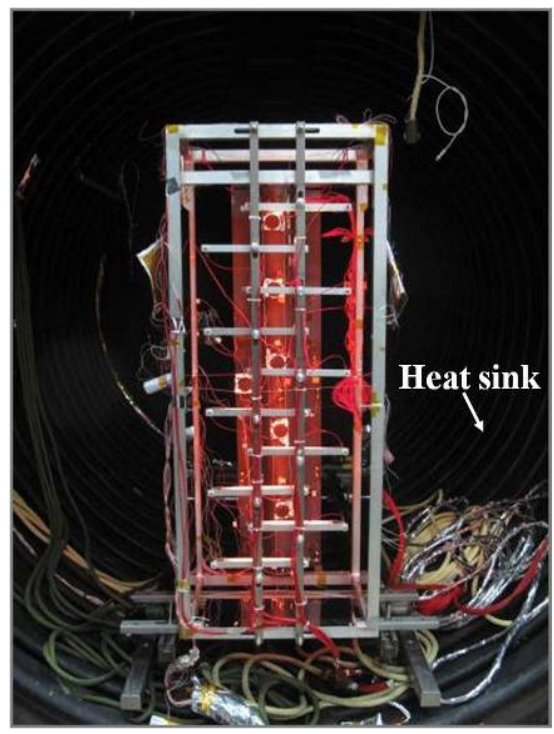

(c) Lightening the infrared lamp

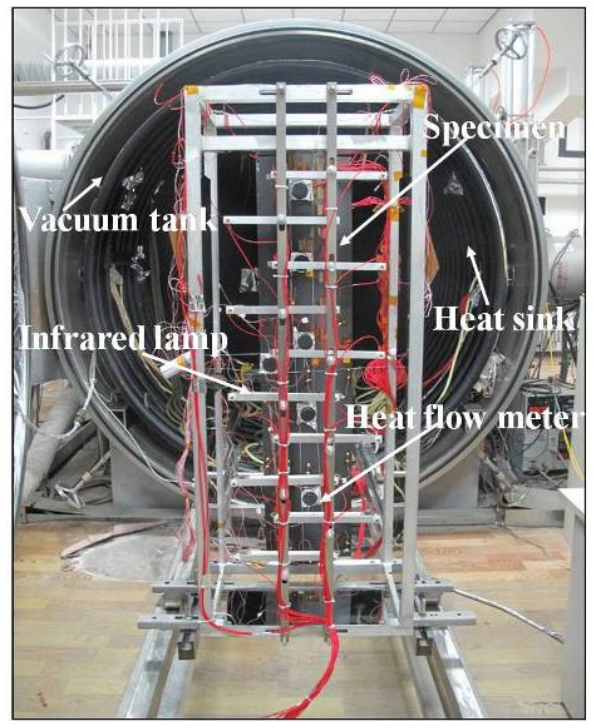

(b) Test system

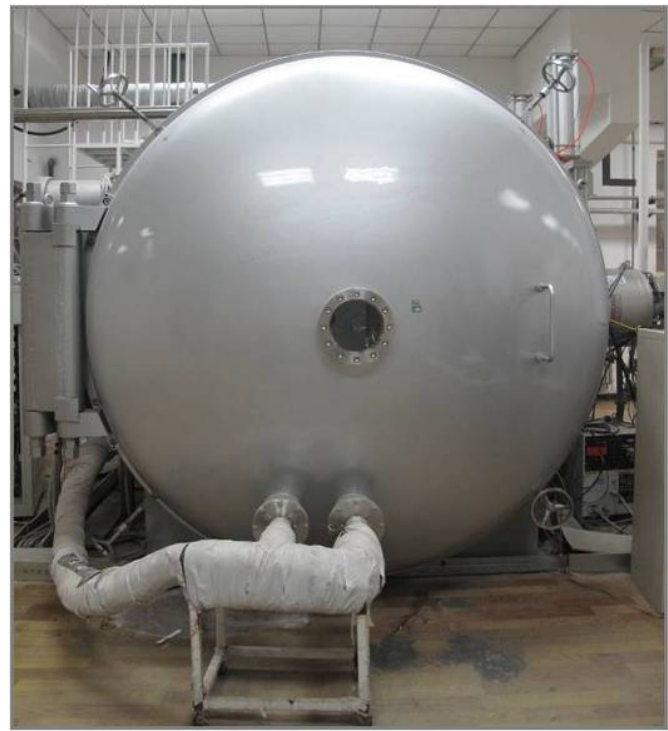

(d) Testing 
Figure 7 Thermal test

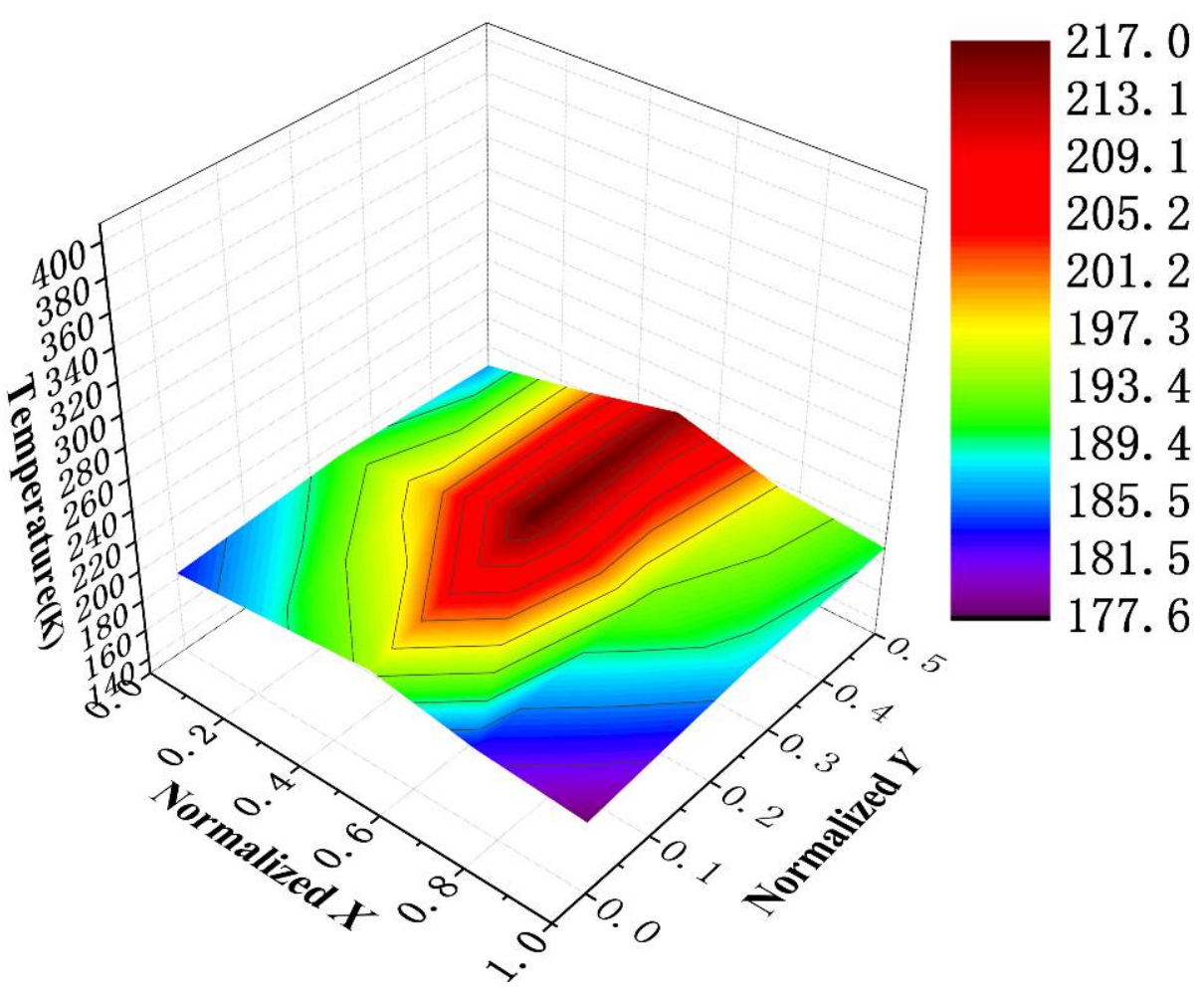

(a) Irradiated part of the DCB

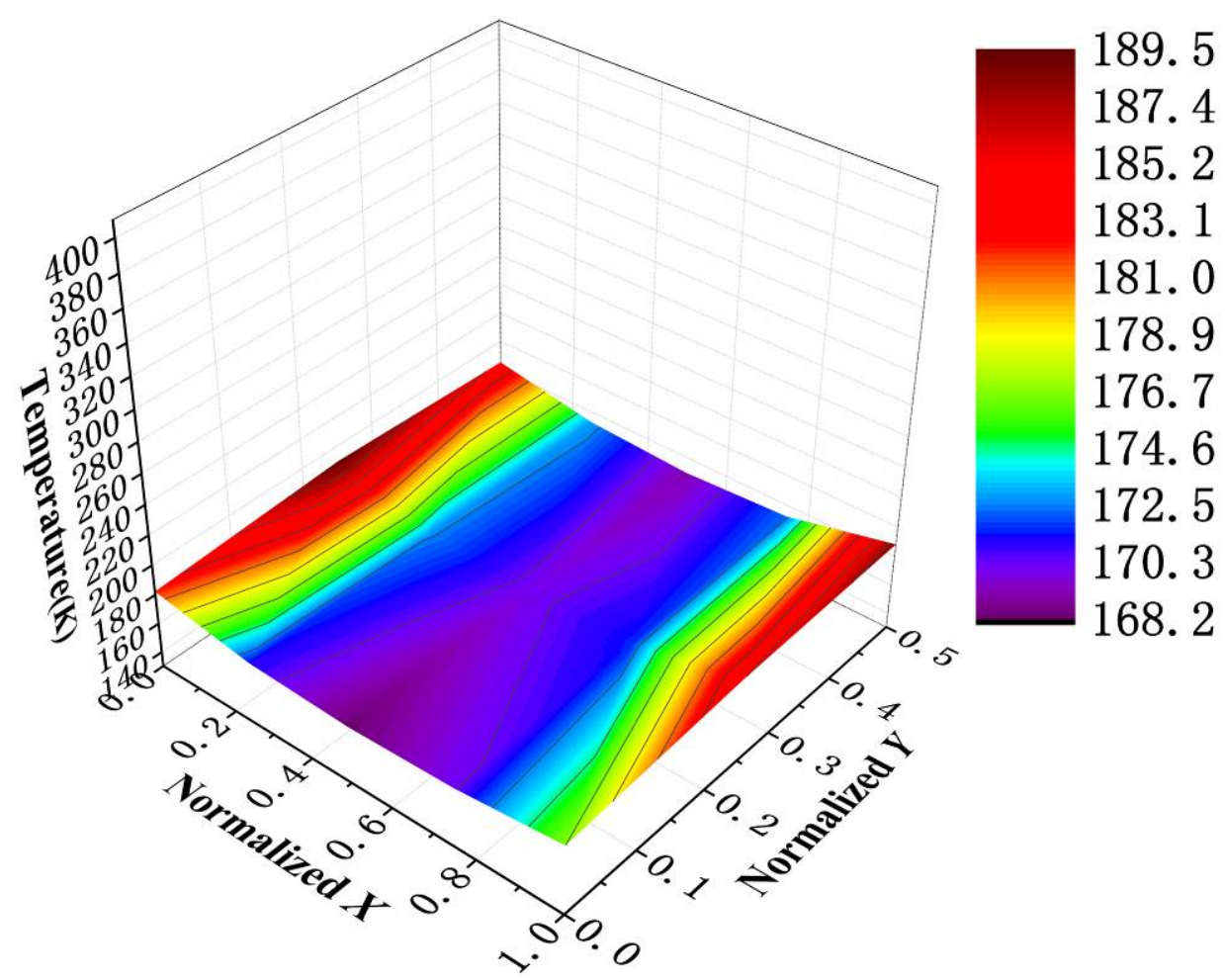

(b) Shadowed part of the DCB

Figure 8 Experimental temperature distribution of the DCB under the heat flux of $200 \mathrm{w} / \mathrm{m}^{2}$ 


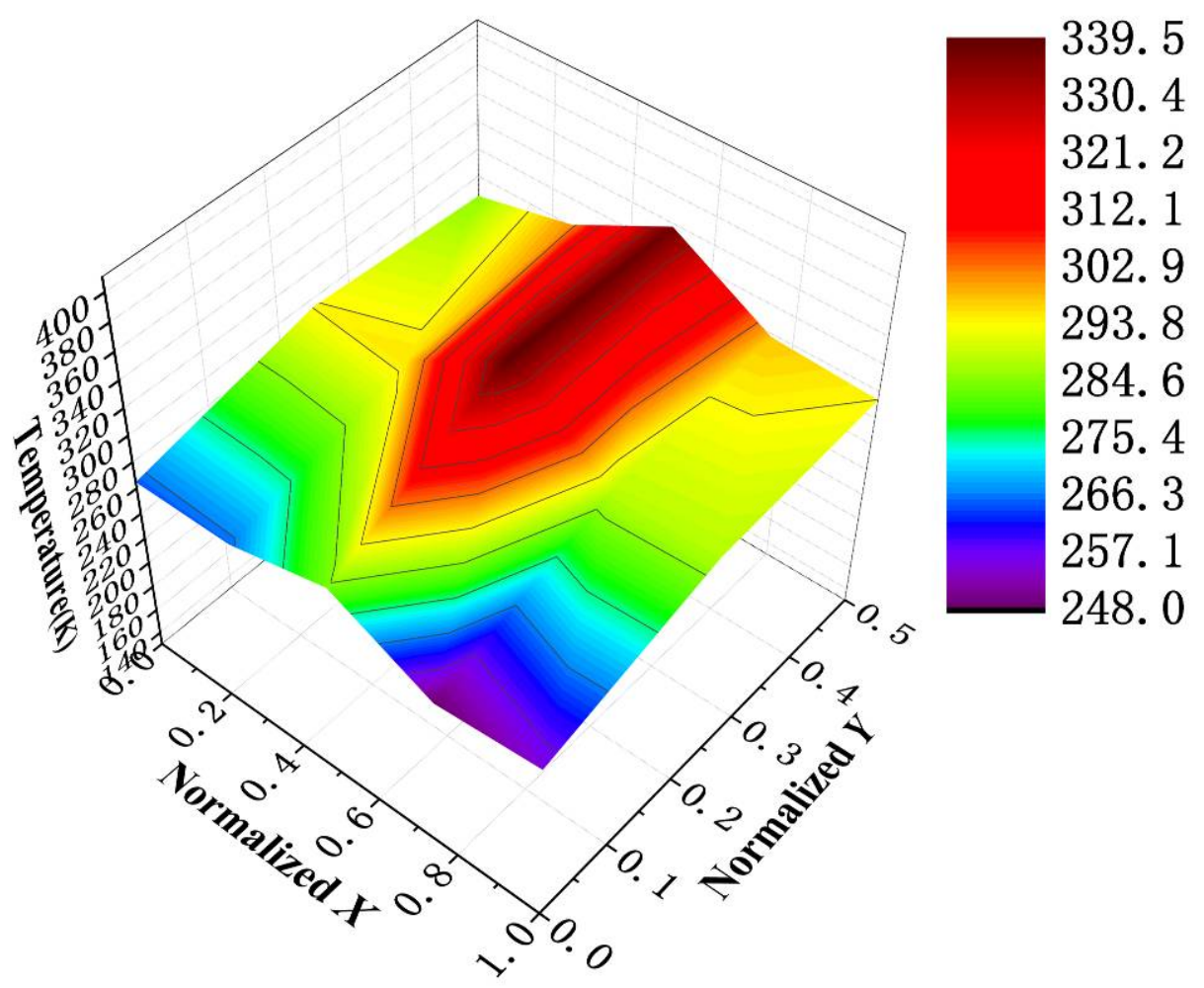

(a) Irradiated part of the DCB

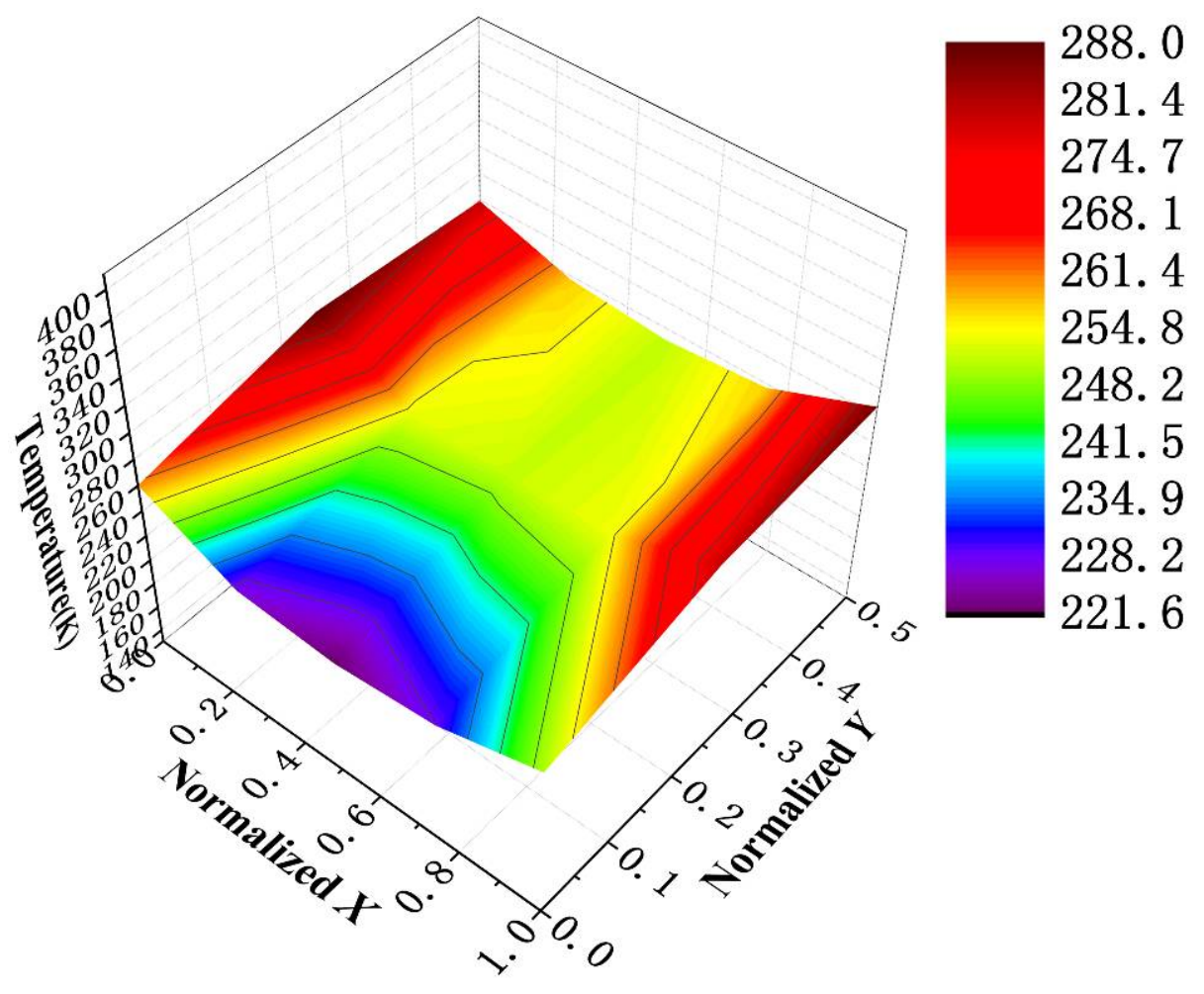

(b) Shadowed part of the DCB

Figure 9 Experimental temperature distribution of the DCB under the heat flux of $1400 \mathrm{w} / \mathrm{m}^{2}$ 


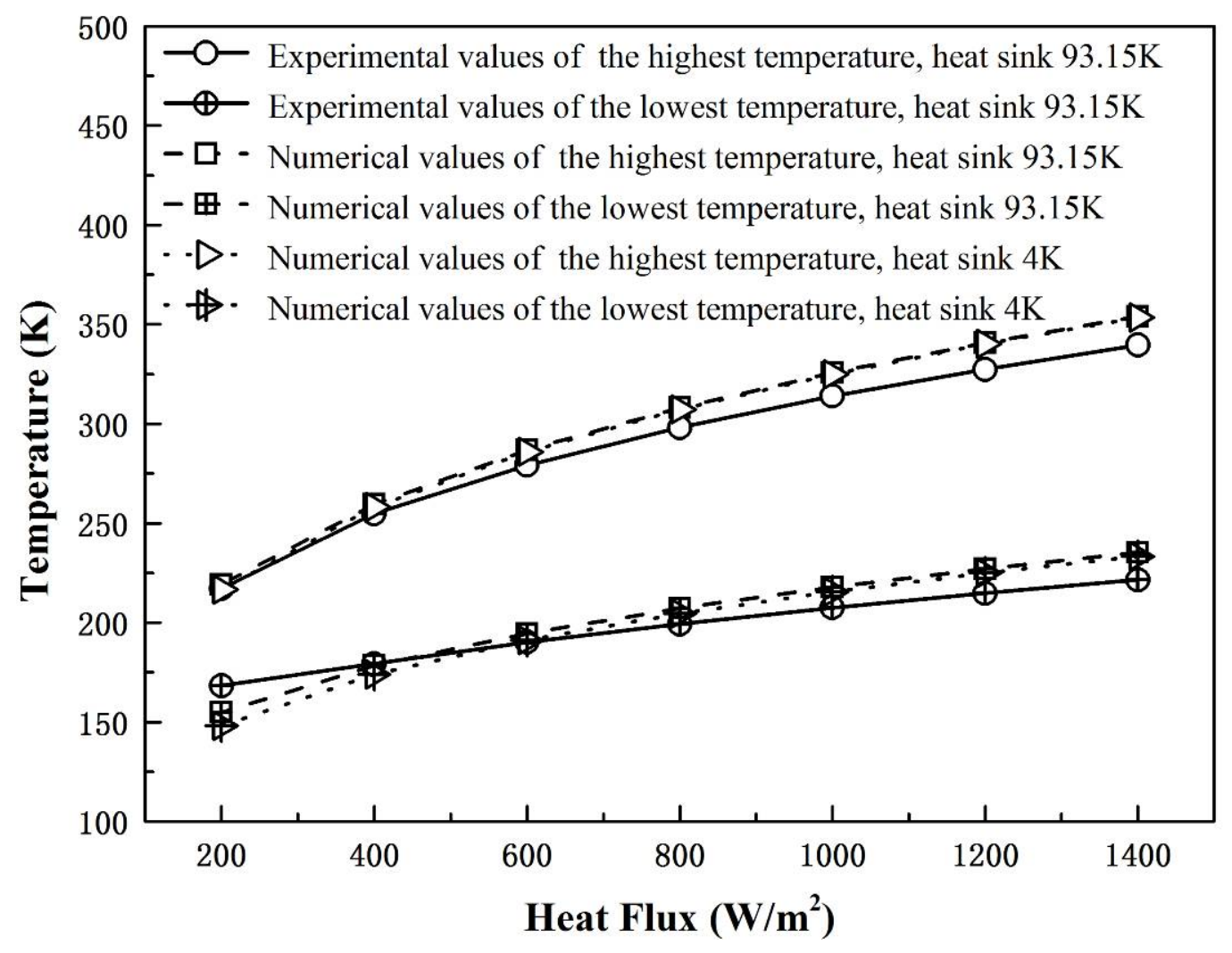

Figure 10 The highest and lowest temperatures of the DCB
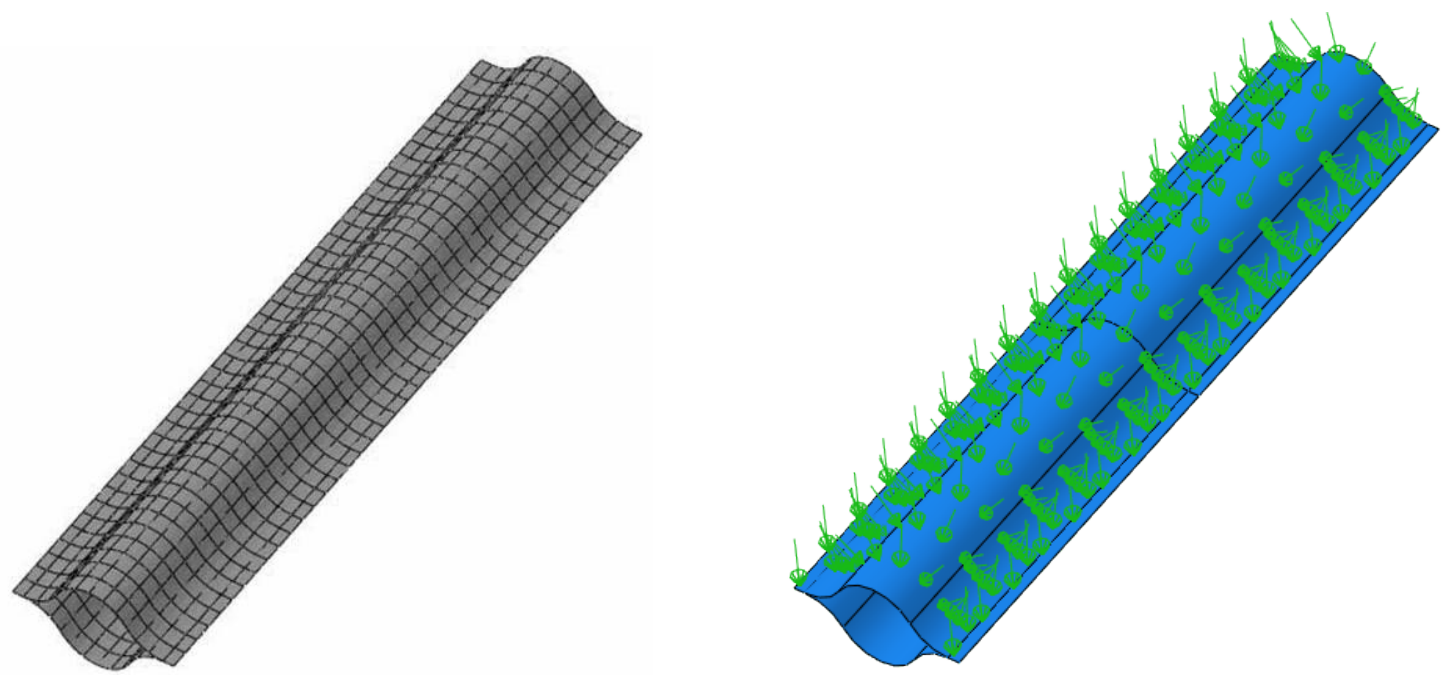

(a) Mesh

(b) Normal component of heat flux

Figure 11 FE model of the DCB in temperature analysis 

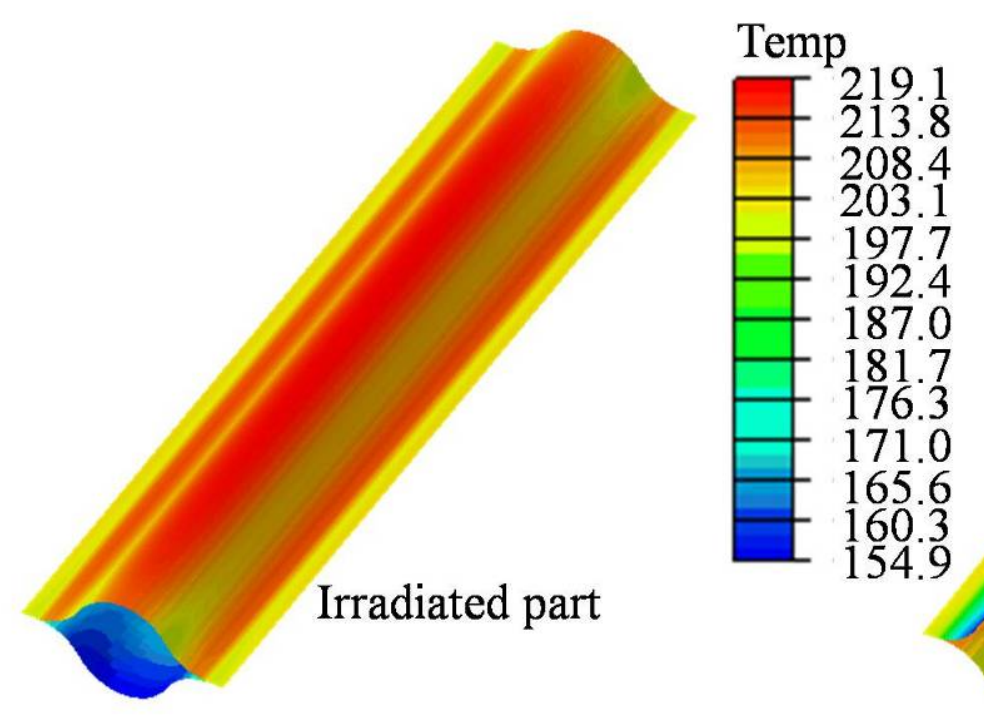

Figure 12 Simulated temperature distribution of the DCB under the heat flux of $200 \mathrm{w} / \mathrm{m}^{2}$

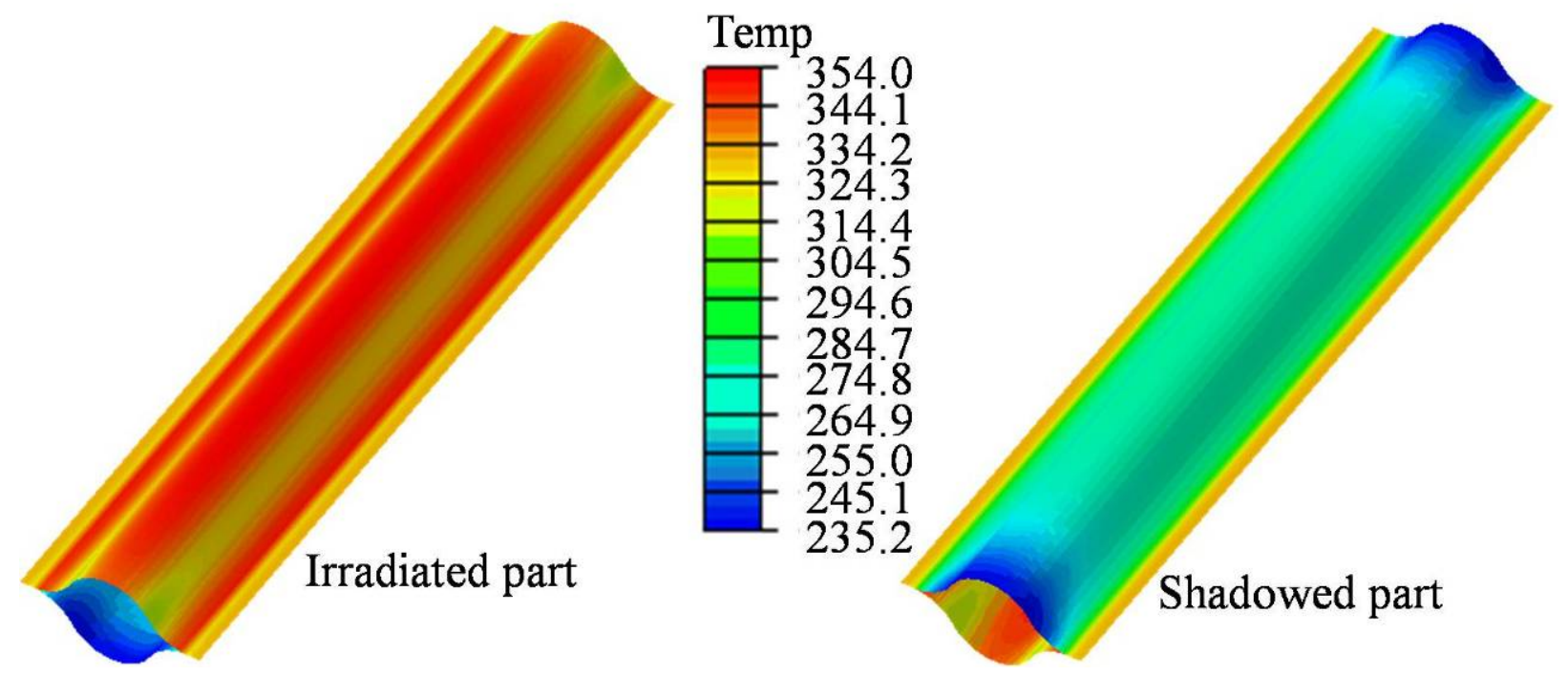

Figure 13 Simulated temperature distribution of the DCB under the heat flux of $1400 \mathrm{w} / \mathrm{m}^{2}$ 


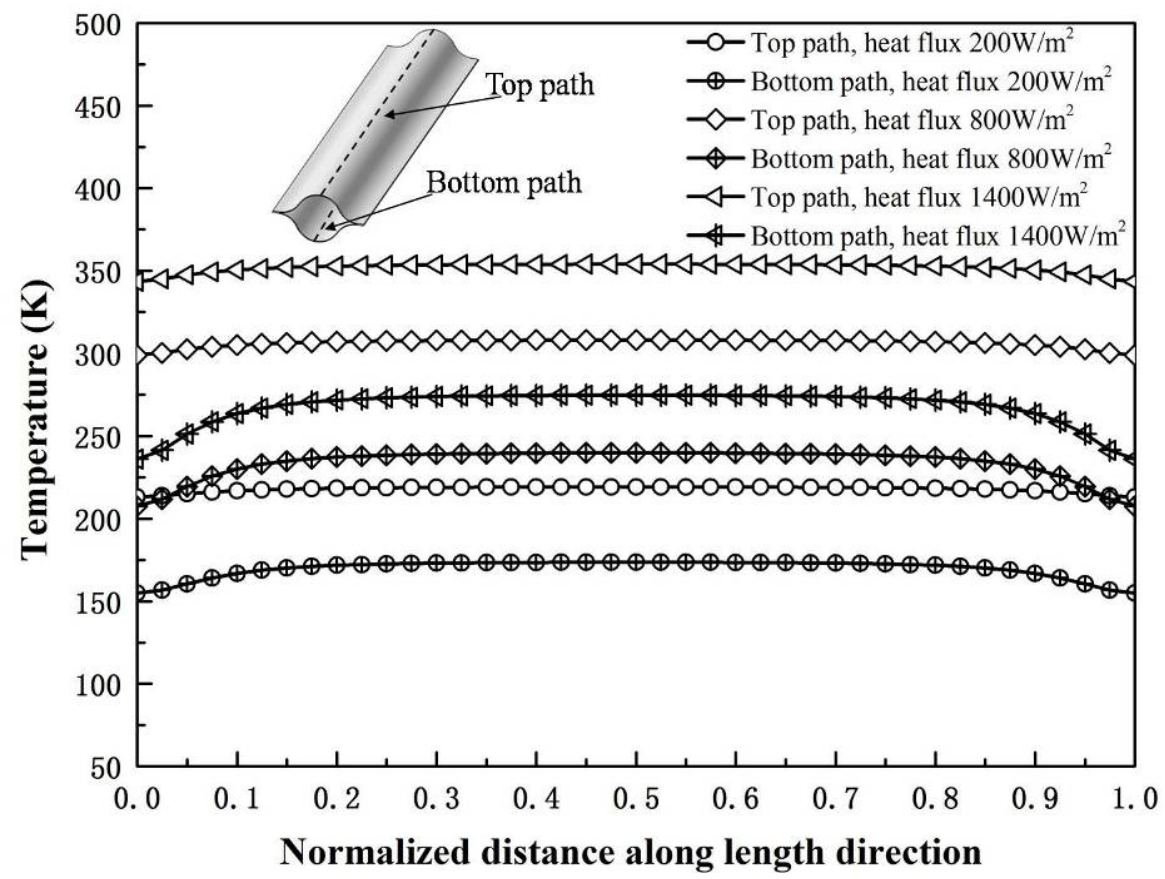

Figure 14 Simulated temperature distribution on the top and bottom paths

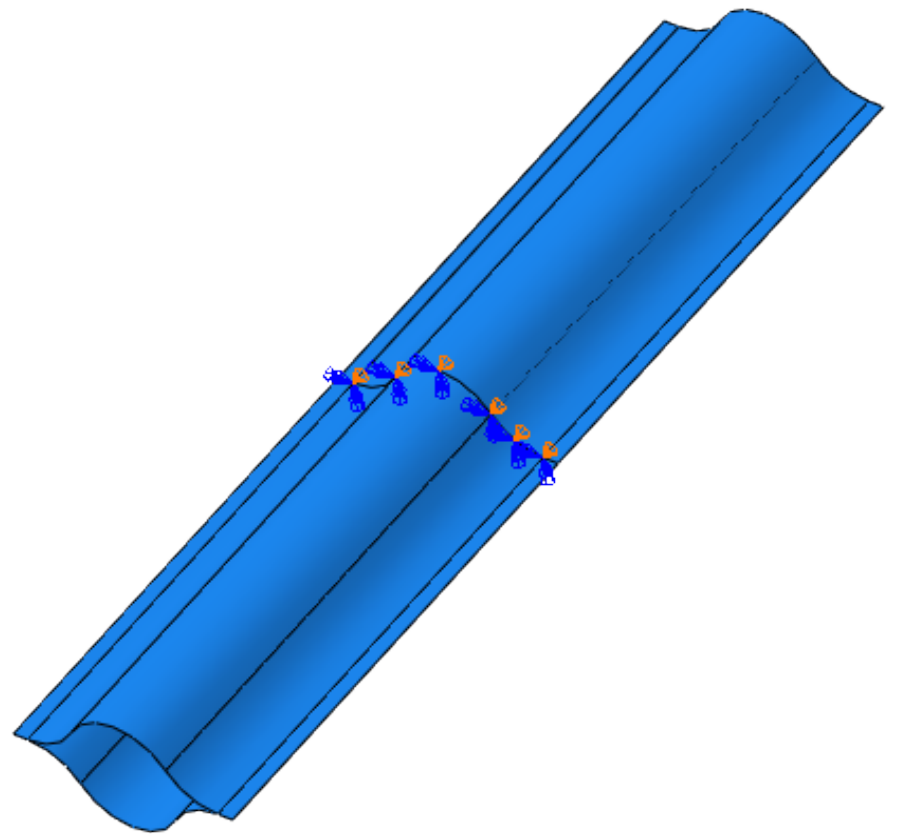

Figure 15 Symmetrical boundary condition of the DCB in thermal deformation analysis 


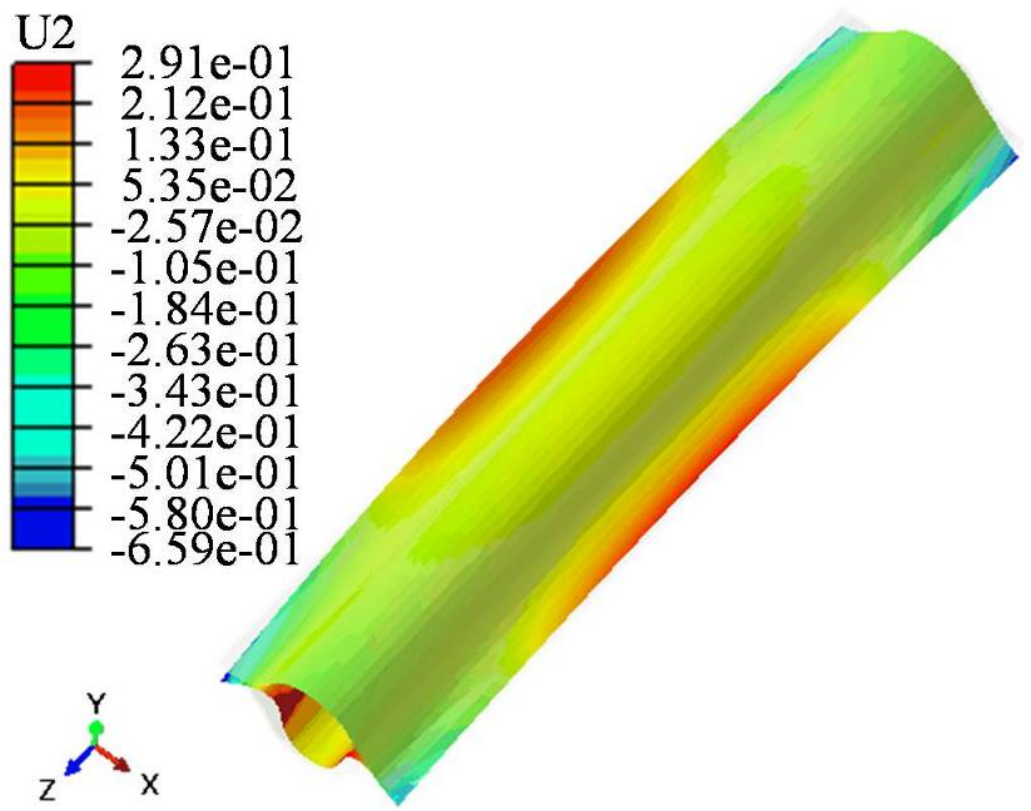

(a) Heat flux $200 \mathrm{w} / \mathrm{m}^{2}$

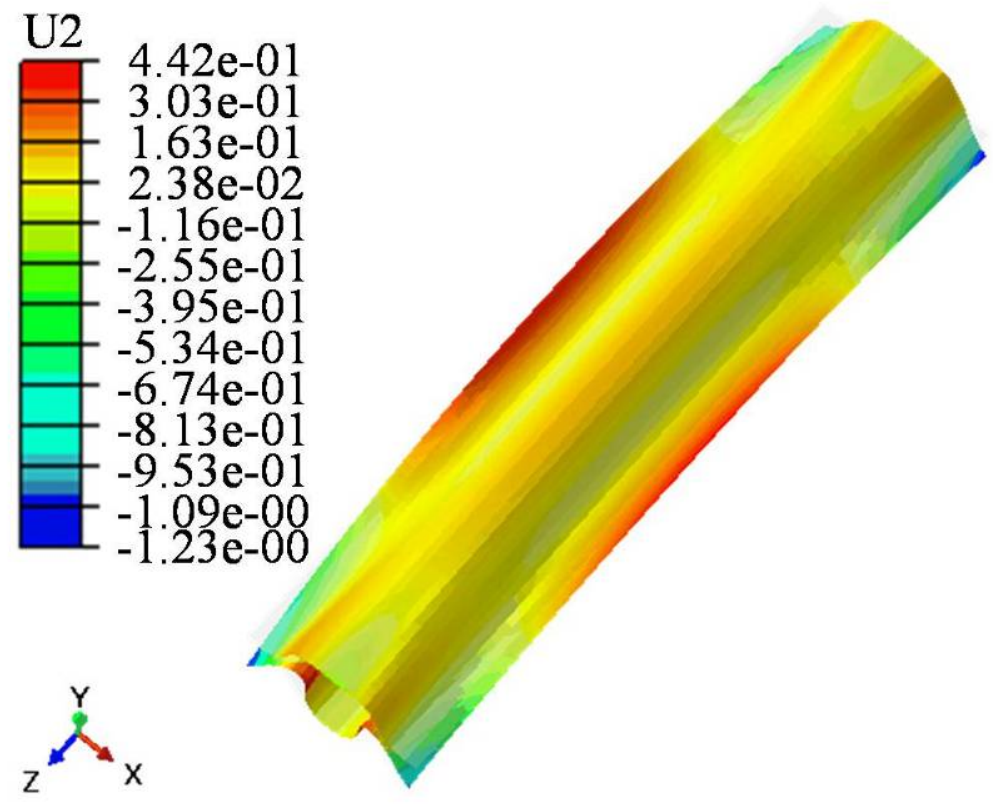

(b) Heat flux $1400 \mathrm{w} / \mathrm{m}^{2}$

Figure 16 Simulated thermal deformation distribution of the DCB 


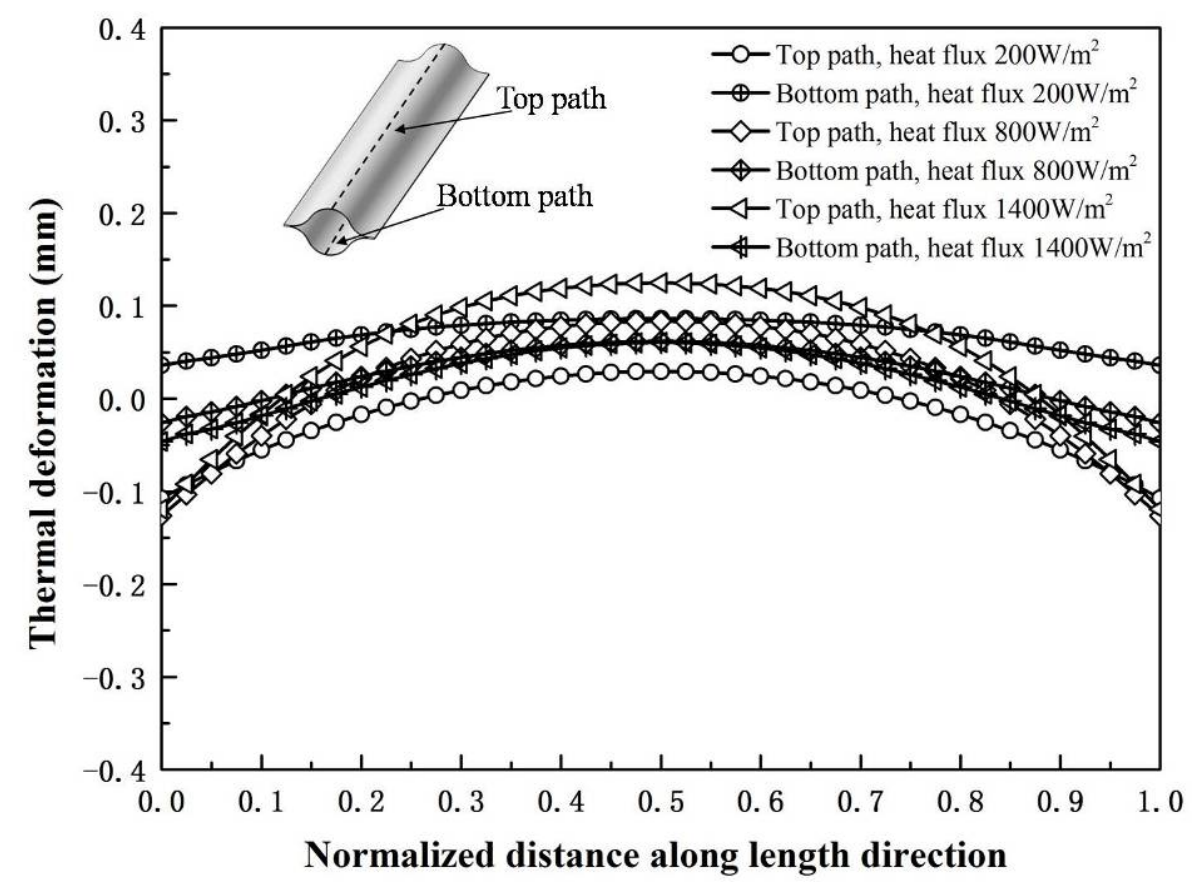

Figure 17 Simulated thermal deformation distribution on the top and bottom paths

Table 1 The highest and lowest temperatures of the DCB

\begin{tabular}{ccccccc}
\hline \multirow{2}{*}{$\begin{array}{c}\text { Heat flux } \\
\left(\mathrm{w} / \mathrm{m}^{2}\right)\end{array}$} & \multicolumn{2}{c}{ The highest temperature $(\mathrm{K})$} & \multicolumn{3}{c}{ The lowest temperature (K) } \\
\cline { 2 - 7 } & Experiment & Simulation & $\begin{array}{c}\text { Relative } \\
\text { deviation }\end{array}$ & Experiment & Simulation & $\begin{array}{c}\text { Relative } \\
\text { deviation }\end{array}$ \\
\hline 200 & 217.0 & 219.1 & $0.92 \%$ & 168.2 & 154.9 & $7.96 \%$ \\
400 & 254.6 & 259.6 & $1.88 \%$ & 179.4 & 178.4 & $0.56 \%$ \\
600 & 279.0 & 286.9 & $2.76 \%$ & 190.0 & 194.5 & $2.26 \%$ \\
800 & 298.2 & 308.1 & $3.32 \%$ & 199.4 & 207.3 & $3.96 \%$ \\
1000 & 313.8 & 325.7 & $3.73 \%$ & 207.6 & 217.9 & $4.96 \%$ \\
1200 & 327.4 & 340.8 & $4.09 \%$ & 214.8 & 227.1 & $5.73 \%$ \\
1400 & 339.5 & 354.0 & $4.23 \%$ & 221.6 & 235.2 & $6.16 \%$ \\
\hline
\end{tabular}


Table 2 Thermal and mechanical properties of Ply

\begin{tabular}{cc}
\hline Properties & Values \\
\hline Longitudinal heat conduction coefficient $\lambda_{1}(\mathrm{~W} /(\mathrm{m} \cdot \mathrm{K}))$ & 6.48 \\
Transverse heat conduction coefficient $\lambda_{2}(\mathrm{~W} /(\mathrm{m} \cdot \mathrm{K}))$ & 1.10 \\
Through-thickness heat conduction coefficient $\lambda_{3}(\mathrm{~W} /(\mathrm{m} \cdot \mathrm{K}))$ & 1.10 \\
Longitudinal thermal expansion coefficient $\alpha_{1}\left(\mathrm{~K}^{-1}\right)$ & $2.13 \times 10^{-6}$ \\
Transverse thermal expansion coefficient $\alpha_{2}\left(\mathrm{~K}^{-1}\right)$ & $32.05 \times 10^{-6}$ \\
Through-thickness thermal expansion coefficient $\alpha_{3}\left(\mathrm{~K}^{-1}\right)$ & $32.05 \times 10^{-6}$ \\
Specific heat $c_{\mathrm{p}}(\mathrm{J} /(\mathrm{g} \cdot \mathrm{K}))$ & 1.12 \\
Infrared emissivity $\varepsilon$ & 0.89 \\
Density $\rho\left(\mathrm{g} / \mathrm{cm}{ }^{3}\right)$ & 1.6 \\
Ply thickness $(\mathrm{mm})$ & 0.03 \\
Longitudinal Young's modulus $E_{1}(\mathrm{GPa})$ & 138.3 \\
Transverse Young's modulus $E_{2}(\mathrm{GPa})$ & 5.8 \\
Through-thickness Young's modulus $E_{3}(\mathrm{GPa})$ & 5.8 \\
In-plane shear modulus $G_{12}(\mathrm{GPa})$ & 2.5 \\
Poisson's ratio $v_{12}$ & 0.3 \\
\hline
\end{tabular}

